\title{
Features of Professional Education of a Music Instrumentalist
}

\author{
Olha V. Ohanezova-Hryhorenko \\ Odessa National A.V. Nezhdanova Academy of Music \\ Ivan D. Iergiiev \\ Odessa National A.V. Nezhdanova Academy of Music \\ Olha V. Muravska \\ Odessa National A.V. Nezhdanova Academy of Music \\ Oleksandra A. Sapsovych \\ Odessa National A.V. Nezhdanova Academy of Music \\ Zinovii P. Burkatskyi \\ Odessa National A.V. Nezhdanova Academy of Music
}

\begin{abstract}
Music education is one of the fields that are extremely popular among Ukrainian young people who are committed to develop and express their creative abilities in the modern cultural space. Thus, despite the difference in the levels of training at the time of entering the university, students of art faculties are interested in learning all the intricacies of the profession of a musician. The purpose of training professional musicians is to form their performing culture, which ensures that students master the basics of vocal and instrumental performance and musical pedagogy. When learning the music, students have to master professional musical performance, accumulate a repertoire, master specifics and techniques immanent to different genres of music, and gain experience in stage performance. As a result, methods and skills that are important for a musician-instrumentalist, which one has to master while receiving professional musical education, are determined. It also considers the artistic training of the future musician and the necessity of practical concert activities for instrumental musicians.
\end{abstract}

Keywords: music pedagogy, artistry, singer, instrumental skill, vocational training, performing skills

\section{INTRODUCTION}

Considering the economic crisis and serious transformations in the socio-cultural sphere, prospects for the development of higher music education are associated with the completion of a number of important tasks. One of them is educating a new type of specialist, which is a musician of a wide range, endowed not only with competencies in one's professional field but also with a developed general cultural outlook, the versatile skills, knowledgeable about the problems of modern musical and cultural life in society. Even in 
the last century, special attention was paid to the training of musical and pedagogical staff, designed to perform only educational but also numerous enlightening functions. The task of popularising music culture and opening it up for the broad audience has determined a multifunctional complex activity of a music teacher who is ready to perform in a variety of capacities: a leader-organiser, choirmaster, illustrator, theorist, methodologist, etc.

Subsequently, with the introduction of a system of narrow specialisation in higher musical educational institutions, dividing students into performers, composers, conductors, teachers, musicologists, etc., the nature of the professional activity of graduates has changed significantly (Chovriy, 2019). Thus, an increasing number of studies have been focusing recently on the need for holistic, versatile training of a musician who has "high professional skills within the wide range of musical and creative activities" (Reeve et al., 2012; Hermina and Sari, 2021; MacIntyre et al., 2018; Cogdill, 2014). Nowadays experts agree that the core of higher music education should be focused on a wider range of educational and practical tasks than just specialised training of musicians in specific programmes. In this regard, it is no coincidence that such concepts as "generalist musician", "universal musician" or "synthetic type of specialist" appear in academic literature (Ponomarev et al., 2019; Yutsevich \& Nikolaunko, 1998).

Notably, during the writing of a musical piece, the author, who is the composer, sets out a number of certain means of musical expression. The composer attempts to influence the emotional state of the listener through a piece of music. However, when a particular piece plays, this effect can be different, depending on many factors. The main task is the ability of an instrumental musician to correctly reproduce a given piece of music, and also not to distort its logic and structure. This ability depends on the skill of the instrumentalist musician. Thus, the development of high skills of instrumental musicians is a priority for both the musician and the teacher (Gish et al., 2012; Li, 2017; Pitts, 2017; Virkkula, 2020). Thus, it is important to note that the level of stage performance is not an individual problem of the instrumental musician. During the training of instrumental musicians, the responsibility partially rests with the educational institution where the musician receives musical education. Every educational institution that trains professional musicians must properly organise its curriculum and educational process. These educational institutions include music schools, colleges, as well as higher education institutions that train professional musicians. To achieve these objectives and goals, every educational institution must organise a number of activities for its students. The most effective events are music competitions and festivals, as well as training conferences, where speakers who are competent in matters of music education are invited. The purpose of this event is to exchange experience both between students and to gain practical and theoretical knowledge from more experienced musicians.

The specific training of future specialists in the area of vocal and instrumental skills should include the use of a multi-style and multi-genre repertoire, mastery of genre and stylistic means. The repertoire, selected by the technical and artistic background of the student, is the essence of the training of future professional musicians (Verina et al., 2021). Therefore, it is important that students study various genres and styles of works by classical composers, contemporary Ukrainian and foreign composers, folk songs with classical sound and new arrangements (Livingstone et al., 2014; Yuen et al., 2019; Prokhorova et al., 2018; Ponomarev et al., 2019). Performing this repertoire requires future professionals to sing and play instruments in different styles, including modern styles. It is important that even the academic education of the future musician allows for revealing all facets of one's talent (de Reizabal \& Benito Gómez, 2020; Pereverzeva et al., 2020; Georgii-Hemming et al., 2020).

It is necessary to emphasise the significant difficulties faced by vocational training systems in various countries, which first indicator is a decline in numbers, while the number of places in higher education is growing rapidly at the same time (Gish et al., 2012; Pisto et al., 2016; Teachey et al., 1991). However, these tendencies vary from country to country, and the survey will help classify different situations, the main reasons for which are different economic strategies. Finally, it will be suggested that significant changes affect the relationship between vocational training and higher education, and that this area deserves further attention in the context of the implementation of the Copenhagen and Bologna processes (Ergiev, 2014; Ohanezova-Hryhorenko, 2020a; Ohanezova-Hryhorenko, 2020b). In terms of vocational training, the analysis focuses mainly on the intermediate level in accordance with conventional views and practices and 
existing data. However, the validity of these boundaries will be carefully examined and a broader approach recommended. And vice versa, this study will not engage in continuing professional education that is based on different principles and requires different research. The purpose is to take a closer look at the difficulties and challenges associated with different approaches to teaching musicians.

\section{MATERIALS AND METHODS}

To achieve the set goal, the authors chose the following approaches: to rethink the category of instrumental and vocal training techniques, fill it with content that meets the essence of this phenomenon in the system of modern practical coordinates and structure of vocational education; to pinpoint the essence of the professional education of a musician as an institution for evaluating the effectiveness and efficiency of the educational system in general; identify the main objectives of various instrumental teaching techniques. When writing the study, general scientific and special methods were used: the method of systemic analysis is a methodology of systems theory, which consists of any objects represented as systems, their structuring and subsequent analysis.

The main feature of systemic analysis is that it includes not only methods of analysis (from the Greek analysis - the dismemberment of an object into elements), but also methods of synthesis (from the Greek synthesis - the combination of elements into a single whole). The main goal of systems analysis is to detect and eliminate uncertainty when solving a complex problem based on finding the best solution from existing alternatives. The systemic analysis allowed for analysing the stages of musician's training within the framework of higher education and to emphasise the necessary teaching techniques and methods.

Content analysis is a method of qualitative and quantitative study of the content of messages to obtain reliable information about social reality. The use of this method involves the algorithmic selection of certain content elements in the text, their classification in accordance with a previously developed scheme, the subsequent calculation of the selected content elements and a quantitative presentation of the results. Due to this method, it was possible to identify the main components of various teaching techniques and their importance in the educational process of a future musician. Benchmarking is a powerful and versatile tool that expands the ability to understand and describe processes and changes in any industry in accordance with the existing reality, concepts and goals of any system. The advantages of various methods of teaching future musicians were determined by using comparative analysis.

\section{RESULTS AND DISCUSSION}

When evaluating the role of academic music education in modern society from different points of view, almost everyone who, in one way or another, touched on this problem in music periodicals, was unanimous that the profound changes that are happening in musical culture undoubtedly require more flexible national music education, adaptation to the realities in the broadest sense of the word. It is obvious that significant and profound changes in the field of musical art in Ukraine were "burdened" by a cardinal socio-historical turn, which inevitably entailed a change in the social system and the economic model of society. It would seem that artistic and socio-economic processes are so far from each other. Moreover, it is in the field of education that they converge in a paradoxical and, at the same time, logical way, exerting a prominent influence on it. So far, this state of affairs is assessed by the music community as extremely negative.

However, this is a reality that only proves that a musician is quite capable of withstanding competition in the labour market, and, therefore, is assessed as a pleasant phenomenon in every sense. After all, this requires not the old narrow professional approach but a broader perspective on music education, the motto of which will be: "Learn music for not becoming a musician, but to become the best in any profession!". At first glance, it seems paradoxical and even "wasteful" in some sense. This statement is dictated by the development of the XXI century labour market in the first place. Inevitably acquiring unprecedented mobility, it will not require narrow professionals, like most musicians of the last century are, but "smart chameleons" who can easily learn new habits, abandon old stereotypes and acquire new ones. And it is music as a "giant accelerator" of the general development of personality, and with musical education, that 
"will give a person what cannot be gained anywhere else". The outflow of graduates of music universities from the profession is not the only problem of modern academic music education. The question of what young specialists will have to face when deciding to stay in their chosen professional field is no less important. Previously, the possibility of applying professional knowledge and skills acquired in a music university was limited to such areas as composing music, teaching, performing, academic activities. They were the focus of university education. For getting on radio and television after a conservatory or institute, in a philharmonic society and in the editorial office of magazines or publishing houses, a young specialist had to study for quite a long time, if not retrain even in previous years. Nowadays, this situation has only worsened, and graduates of music universities generally face a very difficult choice, since a whole layer of new professions has appeared due to the remote transmission of musical information.

The diagnostics, forecasting, as well as regular monitoring of the pedagogical process reveal some contradictions. During the practical sessions, the teacher can identify students who have a higher level of musicality. However, scholars cannot get an exact answer about the development prospects of performing musicians. The concept of musicality is replaced by the content of the professionally important qualities of a performing musician. During the musical performance, several psychophysiological, textured, application, logical and pedagogical constructions are combined, similar to the development of a system of analogies and contrasts in culture and art. In addition, the ability to experience music and express oneself through music, to convey to the listener the desired range of emotions is crucial. These abilities should be closely related to each other, aggregated and synthesised with each other.

The introduction of music education in higher professional colleges highlights a problem of an imperfect school system. The system of music education curricula lacks standardisation and rationality, and the effect of teaching music is not ideal, and it is difficult to fulfil the unique function of music education. On the one hand, music education is mainly performed in the form of non-restrictive electives. The initiative for elective courses is in the hands of the students. It is not given to students who have just entered school and are less knowledgeable on the subject. On the other hand, in the course of teaching the music elective course, the philosophy of the teacher is unfounded, there is no clear teaching goal, teaching plan, and some teachers even do not have professional music teaching materials and no attitude. It is impossible to fulfil the goal of music education to nurture talent in the context of quality education on a fundamental level. Some music practice classes in higher professional colleges are performed by public organisations. Students often use very limited extracurricular time for performances and rehearsals. Higher vocational colleges do not have professional teachers to guide them. In addition, due to many factors such as equipment and venues, it is difficult for the most music practice sessions to achieve relatively good results, which does not fully complete the educational role of professional music training. In addition, some teachers in higher professional colleges still place too much emphasis on teaching basic theoretical knowledge. Most of the classroom hours are used to teach more boring theoretical subjects that require students to memorise complex theories and methods by heart. This concept did not give students enough practical opportunities. This will seriously hinder students from making music and improve their overall academic performance (Renwick \& Reeve, 2012).

Today, it is important to improve university education for students who are able to teach future professional musicians, to acquaint listeners and performers with music of academic genres. As you know, the previously indicated negative tendencies of the rupture of the musical art and the public are not limited to the issues of mastering the stereotypes of its intonation basis. But this task was not fully completed in due time. Nowadays, it is the part of an undeveloped area of professional music education. Another important task, developed in academia but not implemented in educational and pedagogical practice, is the procedure for training musicians and researchers of the state of mass musical consciousness. Thus, this problem has retained its significance. It found a number of unique features and paradoxes. In fact, the current situation in the field of higher education in general and art in particular is paradoxical. Apparently, the listed problems of modern universities often reveal that they are objective but far from new. These problems include the listener's tendency towards music of the academic genres of the past. This problem has been outlined in the past and has not yet been overcome. In this case, it is necessary to emphasise the relevance of the development of new forms of education, ways of solving the problems of preparing the 
"consumer" of academic musical art. The consequence of all this is the necessary solution to complex problems. First of all, there should be an improvement of the system of art education by removing its orientation towards the issues of mass music education in the first place. Direct solution of these tasks of musical education of the listener in the field of finding ways to develop the system of continuous music education according to non-conventional programmes is the training of university teachers and even qualified university teachers. These measures should have been taken for a long time. Nowadays, the questions accumulated through previous decades are compounded by additional elements generated by modernity. This is all for the material and spiritual life of citizens.

All of the above is largely due to the inevitability and irreversibility of the processes that are happening in the world. However, despite these simple explanations, they do not give an answer to the question about the directions and ways of getting out of the current situation, when the further development of these processes can lead to the steady degradation of the entire culture. Consequently, interest in high art, and music in particular, arises most often in childhood and adolescence, and interest in music of "academic genres" is most effectively developed through direct contact with music during "live" performance.

Concert performance is a special form of activity for an instrumental musician. Concert performance has laws inherent only to it, which must be taken into account not only when preparing a concert but also during the entire period of studying musical composition. Every performing musician and musician-teacher should be aware of the specifics of behaviour and way of thinking while performing a piece on stage. An instrumentalist musician should be trained to create a special performance for the piece of music that is intended only for concert performance. In this case, favourable conditions for musical performance are created. Moreover, there is a successful achievement of artistic goals. As a result, the professional and personal development of the musician occurs.

During the concert and performing activity of the instrumental musician, there is a saturation with emotional, physical, and dynamic moments. However, it is important to note that this activity is directed by both the audience and the instrumentalist musician. Musicians are often faced with the problem that they need to vividly and clearly express their emotional state and inner world with its ups and downs, while directing their activities to restrain emotions, preventing them from gaining the upper hand to prevent losing contact with the audience.

Due to being artistic by nature, performance requires a musician to "play" with sound, the ability to perceive and capture sensitively the subtlest gradations of vocal or instrumental intonations transmitted by one. All this presupposes the skill of psychological concentration, enhanced creative attitude and, most importantly, enhanced general artistic attitude. This is artistic and creative activity of the interpreter of the composer's idea to create valuable results of amazing co-creation based on the artistic understanding between all participants in the musical performance, which is often accompanied by a feeling of emotional and spiritual "attraction" in the atmosphere of vocal or instrumental performance. "Wave of will", "internal dynamics" and some other expressions reflecting the psychophysical characteristics of a person, as it turned out, may well be suitable for explaining the vital sources of artistic energy emitted by an artistically gifted person during a musical performance. "Real nature always carries something that goes beyond the ordinary senses. Therefore, the fear caused by art also contains beyond what they contain in itself. And overcoming these feelings enlightens them. Thus, the most important goal of art is achieved".

Another opinion is that the reason prompting a professional musician to adopt the individual artistic experience, standing out against the general personalities - propagandists of the unfading art of oral tradition, lies in the fact of their extremely careful, respectful attitude to the attributive features of the instrument they practice. Thus, in seemingly extremely accessible, unpretentious but as far as possible expressive methods, a striking artistic effect of the highest "fusion" of subject and object is achieved, a truly artistic attitude, fuelled by an inexhaustible belief in the incorruptibility and vitality of the folk performing culture, enriched with a pronounced regional specificity. In other words, the continuation of one of the standard "barriers" that prevent the creation of some kind of integrative approach to the ways of existence of any musical instrument, regardless of its functional purpose in the immense sound latitudes, where artistry, involved in the general channel of the musical performance, appears as an integral part of the personified appearance of the creator of artistically interpreted significant ideas. There is no wonder 
that a creative "compromise" so remarkable in all respects, expressed in a mutually agreed upon "dual world" of different polarities that fall into the vision of a creative instrumentalist musician (teacher, soloist, etc.) greatly facilitates reaching the very "root" of the so-called universal manifestations of musical artistry, regardless of its artistic status and social position in the current cultural community, as well as of the multiple differences in meaningful interpretations of performing techniques, concert repertoire, etc.

\section{CONCLUSIONS}

To sum up, it can be argued that the training of a musician of a wide range is a response to the challenges of the modern reality of the 21 st century, which requires a rethinking of conventional ideas about the profession of a musician, its place and role in society. At the same time, this is a return to the conceptual foundations of Ukrainian music education, an understanding of its experience from the perspective of new socio-economic conditions, where the existing image of a professional musician acquires new motivation, new progressive features and qualities. Among them there are universality, broad erudition, professional mobility, striving to expand professional and cultural interests, flexibility of thinking, exactingness towards oneself, the ability for self-development and self-improvement. Taking into account the current state of the Ukrainian system of higher education, the main direction of its reform should be the liberalisation of higher education, teaching students the principles of freedom and, at the same time, responsibility for their choice. However, only an internally free person who mastered the art of making decisions and taking responsibility for themselves can be a truly conscientious citizen, as well as a competitive flexible professional. The sphere of vocational education, music education in particular, is going through the next stage of its reform now, so the importance of choosing modern methods in the process of vocational training is constantly growing. Professional training in art specialties has always been specific and significantly differentiated in the choice of forms and methods.

In artistic activity, the establishment and development of personality occurs quickly, since art activates all parts of the personality, encourages creativity, which also requires constant personal development. In vocal and instrumental art, a creative personality develops which is capable of solving nontypical tasks and making responsible decisions, especially, young, active and effective ones. For a musician, it is important to master all practical techniques, to develop the missing skills and emerging talents, to understand the specifics of different styles of performing arts, the artistic content of works. In addition, to master the skills of performing arts, it is crucial to use special expressiveness, a variety of techniques and technical means. Concert is also a special form of activity for an instrumental musician. For the successful concert, an instrumentalist musician needs to master certain skills, namely, to understand certain specifics of thinking and behaviour on stage, as well as remember to create a special performance of a piece of music during the concert.

\section{REFERENCES}

Chovriy, S. (2019). European music-pedagogical systems: the retrospective analysis. Bulletin of Mukachevo State University. Series "Pedagogy and Psychology”, 2(10), 51-54.

Cogdill, S.H. (2014). Applying research in motivation and learning to music education: What the experts say update. SAGE Journals, 33(2), 49-57

de Reizabal, M.L., \& Benito Gómez, M. (2020). When theory and practice meet: Avenues for entrepreneurship education in music conservatories. International Journal of Music Education, 38(3), 352-369.

Ergiev, I.D. (2014). Artistry of an instrumentalist musician: Monograph (p.284). Odesa: Astroprint.

Georgii-Hemming, E., Johansson, K., \& Moberg, N. (2020). Reflection in higher music education: What, why, wherefore? Music Education Research, 22(3), 245-256.

Gish, A., Kunduk, M., Sims, L., \& McWhorter, A.J. (2012). Vocal warm-up practices and perceptions in vocalists: A pilot survey. Journal of Voice, 26(1), 11-21. 
Hermina, T., \& Sari, I.T.P. (2021). Analysis of personality model using the big five theory to enhance academic motivation of garut university students. International Journal of Learning and Change, 13(3), 289-300.

Li, J. (2017). Research on musician piano teaching in colleges and universities based on teachers' effectiveness theory. Agro Food Industry Hi-Tech, 28(3), 955-958.

Livingstone, S.R., Choi, D.H., \& Russo, F.A. (2014). The influence of vocal training and acting experience on measures of voice quality and emotional genuineness. Frontiers in Psychology, 5, $156-166$.

MacIntyre, P.D., Schnare, B., \& Ross, J. (2018). Self-determination theory and motivation for music. Psychol Music, 46(5), 699-715.

Ohanezova-Hryhorenko, O. (2020a). Musical artists's talent structure: Immanent musical and professional and organisational moduses Musicological discourse and problems of contemporary semiology: Collective monograph. Lviv-Torun: Liha-Pres, pp. 42-57.

Ohanezova-Hryhorenko, O. (2020b). Autopoiesis as an immanent creative process of the artist and musician//Music semiology: Categories and methods: Collective monograph. Lviv-Torun: LihaPres, pp. 37-55.

Pereverzeva, M.V., Kats, M.L., Ovsyannikova, V.A., Aksenova, S.S., \& Yushchenko, N.S. (2020). Technology and innovation in schoolchildren training: Development of musical and acting skills. Universal Journal of Educational Research, 8(7), 2766-2771.

Pisto, T., Jääskeläinen, V., Ruokonen, I., \& Ruismäki, H. (2016). Instrument Teacher's Narrative Identity and Professional Growth. Procedia - Social and Behavioral Sciences, 217, 443-451.

Pitts, S.E. (2017). What is music education for? understanding and fostering routes into lifelong musical engagement. Music Education Research, 19(2), 160-168.

Ponomarev, G.N., Radionova, N.F., \& Rivkina, S.V. (2019). Bachelors of physical education: Attitudes to vocational training. Teoriya i Praktika Fizicheskoy Kultury, 2019(10), 102-104.

Prokhorova, M.P., Vaganova, O.I., Aleshugina, E.A., \& Trostin, V.L. (2018). Preparation of future pedagogs in vocational training to managerial activities in higher educational establishment. Perspektivy Nauki i Obrazovania, 34(4), 21-25.

Reeve, J., Ryan, R.M., Deci, E.L., \& Jang, H. (2012). Understanding and promoting autonomous selfregulation: A self-determination theory perspective. In D.H. Schunk \& B.J. Zimmerman (Eds.), Motivation and self-regulated learning. Theory, research and applications (pp. 223-244). Routledge, New York.

Renwick, J.M., \& Reeve, J. (2012). Supporting motivation in music education. In G.E. McPherson \& G.F. Welch (Eds.), The Oxford handbook of music education (vol 1, pp. 559-580). Oxford University Press, Oxford.

Riggs, S. (1998). Singing for the Stars: A Complete Programme for Training Your Voice (p.168). Los Angeles, CA: Alfred Publishing Co., Inc.

Teachey, J.C., Kahane, J.C., \& Beckford, N.S. (1991). Vocal mechanics in untrained professional singers. Journal of Voice, 5(1), 51-56.

Verina, N., Titko, J., \& Shina, I. (2021). Digital transformation outcomes in higher education: Pilot study in Latvia. International Journal of Learning and Change, 13(4-5), 459-473.

Virkkula, E. (2020). Evaluating motivational characteristics in vocational music education within the perspective of self-determination theory. Empirical Research in Vocational Education and Training, 12(1), 13-23.

Yuen, M., Yau, F.S.Y., Tsui, J.Y.C., Shao, S.S.Y., Tsang, J.C.T., \& Lee, B.S.F. (2019). Career education and vocational training in Hong Kong: Implications for school-based career counselling. International Journal for the Advancement of Counselling, 41(3), 449-467.

Yutsevich, Y.E., \& Nikolaenko, P.M. (1998). On the Ukrainian singing school. Scientific Journal of the M.P. Drahomanov National Pedagogical University. Series 14: Theory and Methods of Art Education: A collection, 10(15), 184-189. 